Iranian Journal of Applied Linguistics (IJAL), Vol.18, No.2, September 2015, 1-39

\title{
Gender Representation in Interchange (Third Edition) Series: A Social Semiotics Analysis
}

\section{Somayeh Bakhtiari}

M.A. in TEFL, Shiraz University, Shiraz, Iran

Mahboobeh Saadat *

Assistant Professor of TEFL, Shiraz University, Shiraz, Iran

Received 5 April 2015; revised 2 August 2015; accepted 20 August 2015

\begin{abstract}
Gender representation has long been studied in both verbal and visual modes of ELT textbooks. However, regarding the visual mode, research has mainly focused on superficial analyses of how often each gender appears in different roles rather than on how the two genders are represented. The tools proposed in Kress and van Leeuwen's (2006) social semiotics framework, however, permit deep analysis of images taking into consideration how pictorial elements are shown both alone and in relation to other pictorial elements, on the one hand, and the viewers on the other. Following the above-mentioned framework, the present study applied the three dimensions of representational, compositional and interactive meaning presented to 16 photographs randomly selected from the Interchange (Third Edition) series (Richards, 2005) to explore gender portrayals and disclose ideologies in the visual mode of the series. Qualitative data analysis showed some ideologies and stereotypical portrayals, each of which appeared either in one or a few photographs. Taken together, the findings indicated gender bias in favor of men in the series.
\end{abstract}

Keywords: Gender representation; Ideology; Image analysis; Kress and van Leeuwen's (2006) social semiotics; Interchange (Third Edition) series

*Corresponding author: Department of Foreign Languages and Linguistics, Shiraz University, Eram Campus, Eram St., Shiraz, Iran.

Email address: msaadat@ rose.shirzu.ac.ir 
2 Gender Representation in Interchange series: A Social Semiotics...

\section{Introduction}

In recent decades, concurrent use of semiotic modes in multimodal texts and 'visualization of communication' have received more attention than previously (Renekma, 2004, p. 76) suggesting that the significance of the visual mode is not less than the importance of the verbal text. As a result, 'Frequently writing is no longer the central mode of representation in learning materials ... images are increasingly prominent as carriers of meaning ... and writing is being displaced by images as the central mode of representation' (Bezemer \& Kress, 2008, p. 166). Following this trend, English language teaching (ELT) textbooks using various modes of making meaning (verbal and visual) have been categorized as multimodal texts.

Traditionally, knowledge presented in the writings of textbooks dominated knowledge presented in their accompanying images; however, such an unequal writing-image relation has changed to an equal standing on the part of both writing and image (Kress \& Bezemer, 2009). That is, previously images were used as mere illustrations to which students could refer for a better understanding of the knowledge represented through writing, but in the contemporary textbooks both writing and image cooperate equally to convey knowledge. Not only the 'content' of textbooks as a kind of educational media has changed, but also their 'look' has undergone some changes to include semiotic work of design; in other words, the way pedagogic interests are graphically represented on paper has changed (Kress \& Bezemer, 2009, p. 3). The use of pictures to construct meaning by authors and reconstruct it by readers is inevitable. In fact, authors use pictures to encode and readers use them to decode meaning. In the case of EFL textbooks, visuals not only do not lose their importance, but also may contribute more to both conveying meaning and enabling learners to guess the meaning even before reading the written text.

One of the traditional reasons for learning a foreign language is expanding 'individual's cultural horizons, the development of tolerance for 
cultural diversity, and the acquisition of more data for deciding where one fits in the world'. That is, culture learning is a necessary and inevitable phase of language learning and is not separable from linguistic aspects of language (Hartman \& Judd, 1978, p. 383). In fact, textbooks, as the primary source of information about culture (Abdollahzadeh \& Baniasad, 2010), and teachers are the most immediate links between language learners' native culture and the target culture (Otlowski, 2003). Textbooks, including foreign language textbooks, as part of the social context shape their audiences' world views. Therefore, it is important that ELT textbooks represent different aspects of culture and do not impose negative ideologies on learners.

Pictures as significant parts of textbooks play a crucial role in shaping learners' knowledge of the real world (Canning-Wilson, 1999).They portray the outside world and provide learners with more authentic situations; besides, learners' views and perspectives of target language speakers, their culture, society, lifestyle, and even physical features will be directly influenced by the way images in EFL textbooks represent them (Tahririan \& Sadri, 2013). However, they may intentionally or unintentionally expose learners to particular ideologies since as van Dijk (1995) clearly asserts, ideologies can be expressed not only by the verbal mode, but also by the non-verbal semiotic modes such as pictures and movies. In fact, what is realized in the visuals is not an innocent reproduction of the reality but is influenced by the interests of the social institutions (Kress \& van Leeuwen, 2006). Similarly, it is argued that photographs are chosen from among an infinite number of possible sights; hence, they reflect the way the photographer sees the world (Berger, 1972).

Ideologies are, in fact, 'belief systems ... socially shared by all members of a collectivity of social actors' (Van Dijk, 2006, p. 112). These belief systems reflect interests, values, identity, activities and goals of members of a social group (Van Dijk, 2006). Van Dijk (2006, p. 117) asserts that ideologies are not necessarily negative and refers to such ideologies as racist versus antiracist, communist versus anticommunist to illustrate this point: 
4 Gender Representation in Interchange series: A Social Semiotics...

that is while some ideologies serve to 'legitimate domination', some others 'articulate resistance'.

Gender stereotypes have long been studied as a prevalent source of ideologies. Like linguistic texts which may include sex ideologies, visuals lend themselves even more to stereotyping gender identities. For instance, Goffman (1979), one of the scholars in the field of gender representation, indicated that images of advertisements are not pure reflections of the reality about gender roles. He, further, attributed the role of parents to men and that of children to women to define men-women relation in visual advertisements and described the relation in terms of the categories of relative size, feminine touch, function ranking, reutilization of subordination, and licensed withdrawal. In fact, his findings showed that advertisements did not portray women as they were in the real world. Some other researchers (e.g., Bell \& Milic, 2002; Döring \& Pöschl, 2006; Kang, 1997; Linder, 2004) have also shown that Goffman's (1979) categories for female depiction in the images of the advertisements are still common in most of the advertisements though some of the categories are found to be less prevailing. Other stereotypical representations of women tend to depict them as 'being unemployed and involving in domestic roles', 'involving in trivial decisions and actions', 'dependent and needing men's protection', 'isolated from their sex', 'regarded as sexual objects by men', 'found in decorative roles', 'having jobs with low salary' and 'having limited power to purchase' (Belkaoui \& Belkaoui, 1976; Courtney \& Lockeretz, 1971, as cited in Sullivan and O'Connor, 1988). However, Borhart (2003) found that images of female athletes on magazine covers showed them as being powerful. Further research on newspapers, however, has shown that women have been less present in images than in the linguistic text and although they have been linguistically depicted as active in hard sections like political and public life, and civic responsibilities, they have been visually found in conceptual representations and in soft sections such as culture, art, and entertainment (Pinto-Coelho \& Mota-Ribeiro, 2009). 
Women underrepresentation and stereotypical portrayals have also been prevalent in the context of EFL teaching/learning materials. Research has shown that various EFL textbooks included male-dominated bias and underrepresented women in both verbal and visual texts (e.g., Ansari \& Babaii, 2003; Bahman \& Rahimi, 2010; Hartman \& Judd, 1978; Jannati, 2015; Kobia, 2009). Unlike men, who appeared in a wide range of occupations, women were portrayed either in domestic roles such as mothers and homemakers taking care of children, doing house chores, doing the laundry, cooking, making tea, shopping and making a dress (e.g., Amini \& Birjandi, 2012; Hartman \& Judd, 1978; Jannati, 2015; Lee \& Collins, 2008; Mineshima, 2008; Mukundan \& Nimehchisalem, 2008; Otlowski, 2003 ) or only appeared in a limited (stereotypical) range of jobs such as waitress, nurse, secretary and actress and involved in indoor passive activities (e.g., Ansari \& Babaii, 2003; Farooq, 1999; Porreca, 1984; Stockdale, 2006). Being careless drivers and believing in superstition have also been found to be associated with women in the visual mode (Jannati, 2015). Besides, Kordjazi's (2012) study, which adopted Goffman's (1979) gender advertisement categories and relevant dimensions of Kress and van Leeuwen's (2006) social semiotics, revealed that Goffman's categories can also be found in language learning materials (e.g., software programs). The findings of her study revealed that men were shown to be active, competent, dominant and powerful while women were depicted as reactive, object of the male gaze, intimate, subordinate and powerless. The only depiction of women as actors were found in domestic roles doing the chores while men were depicted as reactive and passive only when they appeared with superior status. Men have also been found to be stereotypically represented with negative traits more than women in several studies (e.g. Kobia, 2009; Mukundan \& Nimehchisalem, 2008). Davatgarzadeh (2007), also, revealed that the verbal mode of the Interchange Third Edition Series depicted women to be more prominent, successful, powerful and intellectual as compared to men and represented them in high status positions.

As for the effects of gender representation, existence or non-existence of gender bias in advertising has been shown to bring about willingness or 
6 Gender Representation in Interchange series: A Social Semiotics...

reluctance to apply for specific jobs (Bem \& Bem, 1973).Similarly, it is quite likely that gender-biased textbooks produce a similar effect on language learners' attitudes towards their future occupations (Porreca, 1984). That is, female underrepresentation in foreign language materials limits the female learners' range of roles, desires and expectations and, therefore, short-changes them (Kordjazi, 2012). Indeed, repeated exposure to biased representation of either gender might gradually influence learners' perception of the two genders so that they may internalize such representations and stereotypes, develop sexist attitudes subconsciously (Low \& Sherrard, 1999) and, consequently, reflect them in their actual social, linguistic and behavioral roles (Amini \& Birjandi, 2012).

However, meaning is not merely constructed by the producers of a message (conveyed through linguistic and/or visual modes), but rather those who receive the message are also involved in meaning construction. According to Kress and Bezemer (2009), designs of textbooks take place at two levels:

Communication needs to be seen as a two-stage process, with an initiator/rhetorproducing a message as the 'ground' and an interpreter, on the basis of the 'ground', constructing a 'prompt' for interpretation, leading to meaning which the interpreter takes from the message. (p. 8)

They further assert that the distinction between 'production and consumption' (i.e., writing and reading) has become less clear and that the message is designed at two levels once by the author and once by the interpreter. Therefore, learners' awareness of such ideologies may help them uncover them and avoid such subconscious sexist attitudes.

Although many researchers have tried to uncover ideologies by studying gender representation in the verbal and/or visual modes of the ELT textbooks, they have mostly focused on superficial analyses. With respect to the verbal mode, methods of content analysis have been most prevalent in 
examining gender representation in ELT textbooks. However, regarding the visual mode, the studies did not go beyond counting the number of men or women in the images and generally concentrated on the how often of each gender's depiction rather than the how of their representation. Furthermore, one of the disadvantages of visual content analysis is that images are difficult to count since they are not made up of discrete entities such as words. Hence, it is often far from obvious whether a representation in a textbook counts as one image or as two images' (Bezemer \& Kress, 2009, p. 251). Moreover, as the above literature review indicated, very few of the studies looked at the deep structures underpinning power relations between the represented subjects in the visuals, the viewers and the image producer. Contrary to methods of content analysis which are confined to identifying the exact meaning (Bell, 2001), social semiotics analysis does not yield quantifiable analyses; rather, it goes further to provide a richer qualitative analysis of how and what visuals mean (Bell \& Milik, 2002).

Having asserted that illustrations (i.e. photographs and drawings) of ELT materials play a significant role in stereotyping gender roles and identities since they may reinforce and strengthen biased linguistic text, Hartman and Judd (1978, p. 386) argue that, '... we women and men need to see ourselves represented in ways more closely approximating our own multiformity'. Accordingly, given the importance of gender representation in the visual mode of ELT textbooks, the present study investigated gender representation in the images of a widely used ELT textbook based on a visual social semiotics framework. The rationale behind adopting social semiotics as the framework for this study was that it takes into consideration the deep structures underlining power relations of the pictorial elements with each other, on the one hand, and their relations with the viewers on the other. In fact, like verbal texts, visual texts are whole entities which are constituted by parts. Therefore, merely counting the number of images showing males or females in different roles would not suffice. To understand an image better, we need to take into consideration all parts of it. Social semiotics presents a systematic approach to analyzing image and its components taking into account not only the components but also their 
8 Gender Representation in Interchange series: A Social Semiotics...

relation with other components and the viewer. As such, a brief introduction of social semiotics will be warranted.

\section{Social semiotics}

Social semiotics concentrates on multi-semiotic properties of texts mainly in the contemporary society and investigates visual texts (such as press photographs and television images) and their relation to linguistic texts (Fairclough \& Wodak, 1997). In fact, social semiotics looks into the (re)creation of meaning through the use of semiotic modes including verbal and non-verbal texts. Visuals as the semiotic modes of meaning-making have received particular attention in social semiotics. As Jewitt and Oyama (2001, p. 134) note 'Social semiotics of visual communication involves the description of semiotic resources, what can be said and done with images (and other visual means of communication) and how the things people say and do with images can be interpreted'.

Kress and van Leeuwen's (2006) visual social semiotics was initially developed based on Halliday's systemic functional linguistics and is an approach to visual analysis that signifies the role of context in the (re)creation of meaning in the visuals (Kress \& van Leeuwen, 2006). According to social semiotics, every single person in a special social context is surrounded by and provided with a range of semiotic resources (Kress \& van Leeuwen, 2006). The term resource is a key term in social semiotics and derived from the work of Halliday in that he considers grammar a resource, rather than codes or rules, which is used to make meaning (van Leeuwen, 2005). Unlike Paris School Structuralist Semiotics (according to which if people know the same code which connects a special meaning to a particular sign, they will be able to understand the meaning conveyed by that special code irrespective of the context), social semiotics emphasizes the importance of the context which entails the use of different kinds of rules and emphasizes the role of both cultural histories and cognitive resources that combine to create semiotic resources to produce or interpret 
messages, both visual and linguistic (Jewitt \& Oyama, 2001). Van Leeuwen (2005, pp. 3-4) comments that in social semiotics the term resource is preferred, because it avoids the impression that what a sign stands for is somehow pre-given, and not affected by its use [emphasis in the original]'. In fact, according to van Leeuwen (2005, pp. 3-4), the past uses of resources have constituted a 'theoretical semiotic potential [emphasis in the original]' that is known by the message producers. In other words, experience and cultural variables may add or subtract potential meanings to a signifier which compels us to decode it in its context rather than apart from its use.

In the grammar of visual design, signs are not considered arbitrary, but rather they are motivated with respect to the sign producer and the context of sign-making (Kress \& van Leeuwen, 2006). Put differently, not only does the sign represent a message, but also knowledge of the rules used by the sign producer lets the exact intended meaning which is implicit in the how of the sign caught by the viewer; hence, the context of representation is a major factor on which the reproduction of the message is dependent.

Having employed Kress and van Leeuwen's (1996[2006]) visual social semiotics, either solely or in conjunction with other frameworks, researchers have shown how different visual factors manipulate meaning in the visual texts of different magazines, newspapers and advertisements (e.g., Bell \& Milic, 2002; Bohlke, 2006; Borhart, 2003; Godeo, 2009; Lin \& Ihara, 2009; MartínezLirola, 2009, 2010; Manolache, 2010; Oyama, 2007; Pinto-Coelho $\&$ Mota-Ribeiro, 2009). However, to the best of the researchers' knowledge, very few studies have examined gender representation in the images of ELT materials (e.g., Kordjazi, 2012) and textbooks (e.g., Tahririan \& Sadri, 2013) based on Kress and van Leeuwen's (2006) visual social semiotics. Accordingly, to fill this gap, the present study strives to answer the following questions applying Kress and van Leeuwen's (2006) social semiotics to the photographs in the Interchange (Third Edition) series (Richards, 2005) which is widely used in the world to teach English as a second/foreign language: 
10 Gender Representation in Interchange series: A Social Semiotics...

1. How are men and women represented in the photographs of the Interchange(Third Edition) series?

2. To what extent is there any gender bias in the photographs of the Interchange (Third Edition) series?

\section{Methodology}

\section{Materials and data collection procedures}

The photographs for data analysis were chosen from the Interchange (Third Edition) series, written by Jack C. Richards (2005) and published by Cambridge University Press. This series includes four volumes covering the beginning level to the high-intermediate level.The choice was made based on the following rationales. As mentioned before, the series is declared to be the most successful one used to teach North American English to (young) adult learners around the globe.The series is also widely used in many Iranian language institutes. Furthermore, it has been claimed that the current approaches to teaching and learning languages have been incorporated into this edition. Indeed, these rationales lent support to the speculation that the books merited close scrutiny in terms of gender representation.

To avoid heterogeneity of the sample and to make comparison possible and less complicated, the researchers found it necessary to compare gender representation either in photographs depicting only one gender (either men or women) or in photographs including both genders. The preliminary analysis showed that most of the categories of the framework were applicable to the images which included both genders. In addition, the focus of the current study was to investigate the representation of men and women in relation to each other. Therefore, only photographs including both genders (one or more than one male together with one or more than one female) were used and photographs including one single gender were excluded. As such, out of the total number of pictures (69) in the series, twenty percent (16 photographs) was randomly chosen. Indeed, four photographs chosen through random sampling from each volume provided the necessary data for the present study. The pictures thus selected were 
scrutinized based on the components of the framework (Kress \& van Leeuwen, 2006) employed in the study which will be briefly introduced in the following section.

\section{Analytical framework}

The model adopted for the critical visual analysis in this study is the visual social semiotics developed by Kress and van Leeuwen (2006). Following Halliday's idea that there are three major metafunctions for semiotic modes (i.e., ideational, interpersonal, and textual), Kress and van Leeuwen (2006) reflected these metafunctions in their work of visual analysis turning them into representational (how the visual elements are related to each other), interactive (how the image producer and viewer interact, on the one hand, and how they interact with the depicted elements, on the other) and compositional meanings (how visual elements are placed in the visual text) to apply them to visual structures (Kress \& van Leeuwen, 2006; van Leeuwen \& Jewitt, 2001). The following concepts and their explanations taken from Kress and van Leeuwen's (2006) Reading Images summarize their social semiotics framework.

\section{Representational meaning}

The representational dimension refers to 'visual syntax' which is defined as meaningful patterns which relate the represented participants (i.e. the depicted elements) to each other. These visual syntactic patterns are divided into narrative representation and conceptual representation which are defined below. In the narrative representation, the represented participants are depicted in the process of doing something and involved in actions, events or processes of change. Such a line of action is shown by vectors (oblique lines formed by eyelines, outstretched arms, bodies, tools, etc.) which serve to connect the participants together and/or make them involved in the process of action. Action processes, reactional processes, speech processes, mental processes and conversion processes are different categories of narrative processes. The conceptual representation deals with the "generalized and more or less stable and timeless essence" of the 
12 Gender Representation in Interchange series: A Social Semiotics...

represented participants such as class, structure or meaning (Kress \& van Leeuwen, 2006, p. 59). Classificational, analytical and symbolic processes are different categories of conceptual processes.

\section{Interactive meaning}

This dimension deals with the (imaginary) relationship between the represented participants and the interactive participants (the image producer and the viewers) and is realized by the gaze, size of the frame, perspective, and horizontal and vertical angle. Images are divided into two categories with respect to the presence or absence of gaze: demand (in which the represented participants demand something from the viewers by looking straight at their eyes) and offer (in which the represented participants do not look directly at the viewers and are offered to the viewers as objects of the viewers' scrutiny. Size of the frame, ranging from very close shot to very long shot, is used to establish varying social distance between the represented-interactive participants. Perspective refers to subjective or objective representations and specifies the point of view. Horizontal angle deals with the oblique or frontal angle between the represented participants and the viewers which brings about detachment or involvement, respectively. Vertical angle may also manipulate the power relations between the interactive participants and the represented participants by depicting the latter from the high angle, low angle or eye level.

\section{Compositional meaning}

Compositional meaning deals with how the representational and interactive elements are made to connect to each other and how they are connected to make up a meaningful whole. Information value, salience and framing are the three elements which can manipulate compositional meaning. Different zones of an image have different informational values: while right is the area of the new, left is the zone of the already known information with which the viewer is supposed to be already familiar; while the top section 
shows the ideal information, the bottom section is the place of the real information; while the centre is the place of the core, the margin is the zone of dependent parts. Salience refers to such factors as size, color contrasts, and placement in the visual field of pictorial elements which are intended to attract the viewers' attention. And finally, framing can connect or disconnect the represented participants by concrete framelines, white space between elements, and dividing lines produced by means of other devices.

\section{Results}

In this section, results of the analysis of the sample photographs are presented. The patterns of gender representation found in the analysis are each discussed and illustrated using one or two photographs from the sample. However, to save space, only the most salient and prominent semiotic features of each of the images are presented. Figures 1 to 9 will appear in the body of this section. For figures 10 to 16, refer to pages 57 (the first image placed on the right), 86 (the image placed on the top right side) of the first level volume, pages 34 and 47 of the second level volume, page 71 (the image placed on the right side) of the third level volume, and pages 15 (the image placed on the top) and 93 (the image placed on the top) of the fourth level volume of the Interchange (Third Edition) series (Richards, 2005).

It is worth mentioning that most of the categories of the three metafunctions could be and were applied to the sample photographs except a few categories (e.g., the speech process, some of the categories of the analytical process) which should be applied to specific kinds of images (e.g., images including speech balloons, diagrams, and those displaying partwhole relations). In fact, generally, all aspects and categories of the framework can contribute equally well to discovering ideologies. However, in terms of gender representation, some of the categories were more revealing while others, having been applied to the photographs, did not show any specific pattern of ideological representations. In fact, to make use of Kress and van Leeuwen's (2006) social semiotics, one should take into consideration some particular aspect such as gender representation because 
14 Gender Representation in Interchange series: A Social Semiotics...

this framework is a 'tool for use in critical research', not 'an end in itself' (Jewitt \& Oyama, 2001, p. 136).

Social semiotics is not 'pure' theory, not a self-contained field. It only comes into its own when it is applied to specific instances and specific problems, and it always requires immersing oneself not just in semiotic concepts and methods as such but also in some other field. (Van Leeuwen, 2005, p. 1)

The analysis of the sample based on the three metafunctions of representation, interaction and composition proposed in Kress and van Leeuwen's (2006) social semiotics showed the following patterns in some of the sample photographs.

1. Both men and women were found innarrative representations depicted as activein jobs or activities which are stereotypically conceived of as female preserve (e.g., nurse, cook and teacher) (figures 1, 4, 10 and 15).

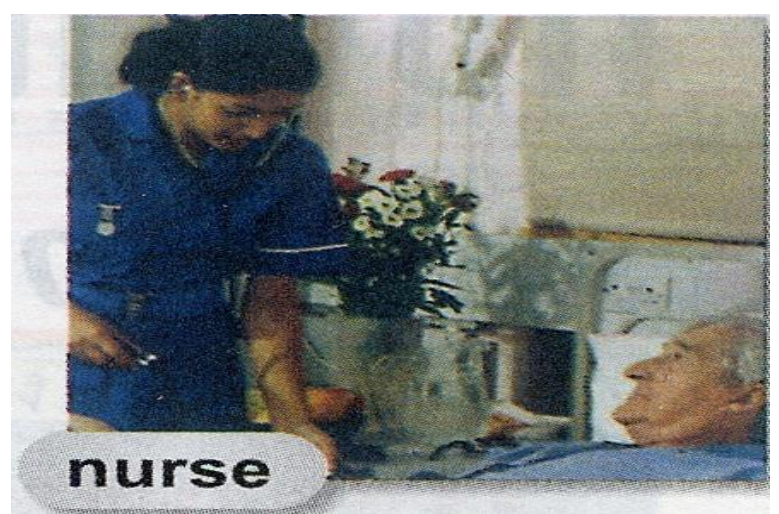

Figure 1: Interchange Student's Book 1 (Richards, 2005, p.

$15)$. 
For instance, in Figure 1, an old man and a woman are the represented participants of the image. The woman is a nurse, as it is mentioned in the caption of this image. Nursing is one of the jobs which is stereotypically believed to be suitable for women. The arms of the woman form vectors directed at the man in a way that she seems to be doing something (i.e., taking blood pressure) to the old man who is depicted as a patient. The woman is, therefore, the actor of a transactional action process in which the man is the goal. In fact, transactional actions are equivalent to sentences with transitive verbs in which the actor stands for the agent and the goal stands for the object of the sentence. Hence, if we wish to use words to convey the same meaning conveyed by this image, we would say: The nurse is taking the old man's blood pressure- a sentence including a transitive verb with an object (the old man's blood pressure) and the woman as the subject of the sentence. Thus, as a nurse, the woman is shown active and involved in a narrative representation rather than a conceptual one. It is worth mentioning that while narrative representations contribute to stress active engagement and involvement in particular roles, conceptual representations serve to emphasize inactivity in these roles.

Moreover, horizontal angle of representation may also intensify this kind of representation. That is, the frontal plane of the woman in Figure 1 is parallel to the frontal plane of the viewer. Therefore, she is depicted as someone who belongs to the viewer's world: women's being active in such kinds of jobs is a normal fact in the viewer's world.

Information value is another factor contributing to this stereotypical portrayal: the woman as a nurse shown in a narrative transactional action process is placed on the left side; that is, women as nurses are represented as an already known fact, as given and part of the culture.

Another example of women's active appearance in stereotypical activities is Figure 4 in which the woman is shown while preparing the food. Cooking is also a stereotype of women. In this photo, the woman's arms make diagonal lines aimed at the food; thus, she is the actor and the food is the goal in a transactional action process. In other words, the woman is 
16 Gender Representation in Interchange series: A Social Semiotics...

represented as active while cooking. This may be interpreted as ideological: The woman appears in the stereotypical activity of cooking.

Men are also depicted in narrative representations (transactional actions) as a chef, a hairdresser and a school basketball coach (figures 4, 10 and 15, respectively) while doing their jobs. Such jobs, however, are stereotypically thought to be suitable for women. Therefore, it can be inferred that in the sample photographs such jobs are not attributed merely to women, but rather to both genders.

1. While men as fathers are mostly depicted in conceptual representations (de-emphasizing the role of fathers), women as mothers are represented in active, narrative representations (emphasizing the role of mothers) (figures 2 and 12).

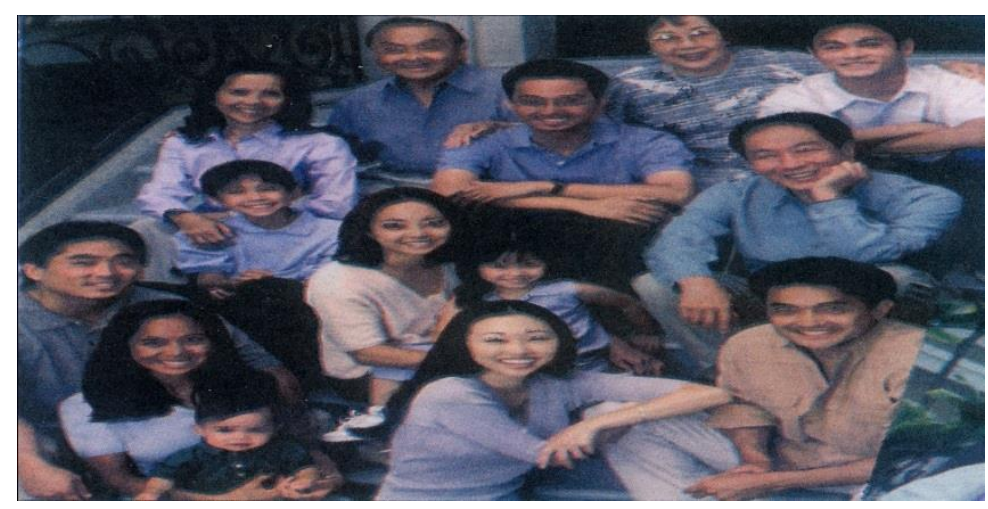

Figure 2: Interchange Student's Book 1 (Richards, 2005, p. Interchange 5).

According to the title of the relevant exercise in the textbook, Figure 2 depicts the members of a family who constitute the represented participants of this image. With respect to the female participants, vectors are formed by the arms of five women; thus, there are five action processes identified in this picture. 
1. The old woman (who seems to be the grandmother of the family) placed on the top right side has put her arms round two men who seem to be her (grand) sons. Thus, vectors formed by her arms directed at the two men indicate that she is the actor of a transactional action process in which the goals are the two men.

2. The woman placed on the top left has put her hand on the shoulder of the boy who is sitting in front of her; thus, she is the actor of another transactional action in which the vector is directed at the boy who seems to be her son. The son is, therefore, the goal of this narrative visual structure.

$3 \& 4$. The woman in the center and the woman at the bottom left have put their arms round the girl and the baby placed in front of them, respectively. Vectors are formed by their arms aiming at the girl and the baby who seem to be their children. Therefore, they are the actors of the transactional action representations in which their children are the goals.

5.The arms of the woman at the bottom right are on the man's leg and form vectors aimed at the man. She is, thus, represented as the actor of a transactional action process in which the man is the goal.

Accordingly, the female participants represented as actors of the aforementioned transactional processes except number 5 are depicted as active in a narrative representation, which can be interpreted as ideological because they are ideologically portrayed as active in the stereotypical roles of mothers taking care of their children. In other words, the role of mother for women is emphasized by the narrative representation.

The male participants, however, are represented in conceptual structures and in a timeless and stable essence rather than doing something to somebody because no vectors are emanated from them. Only two male participants in this picture are represented in narrative processes in which they are involved in narrative conversion processes explained below. 
18 Gender Representation in Interchange series: A Social Semiotics...

1. The woman at the bottom left side of the image, on the one hand, is the actor with respect to a participant (her baby who is the goal of an action process) and, on the other hand, she is the goal with respect to another participant (her husband who is the actor of another action). Thus, the woman has been depicted as relay and there are two ideologies in this visual structure: (1) the woman is shown as active in the role of a mother taking care of children, (2) the man is portrayed in a stereotypical depiction in which he is powerful and supportive to his wife and family and his wife is dependent on him.

2. Another conversion process identified in this image involves the old man on the top left side and the woman and her child on the top left side. The woman is simultaneously both the actor and the goal: the actor of a transactional action process in which her child is the goal and the goal of a transactional action process in which the old man (who seems to be the grandfather of the family) is the actor. The arm of the grandfather makes a vector aiming at the woman, and, therefore, the same two ideologies mentioned in the previous conversion process are also present here.

Therefore, in this picture, all men (in the roles of fathers or husbands) except two of them are shown in conceptual rather than narrative processes. That is, their role as father is deemphasized by the conceptual depiction.

Moreover, the three women involved in transactional processes are depicted as active in the role of mothers and the two men involved in conversion processes upon whom the family is depicted to be dependant are placed on the left, shown as already known information or part of the culture and agreed upon by the viewer. 


\section{Compared to men as consumers, women as consumers are depicted as some usual fact (figures 3 and 11).}

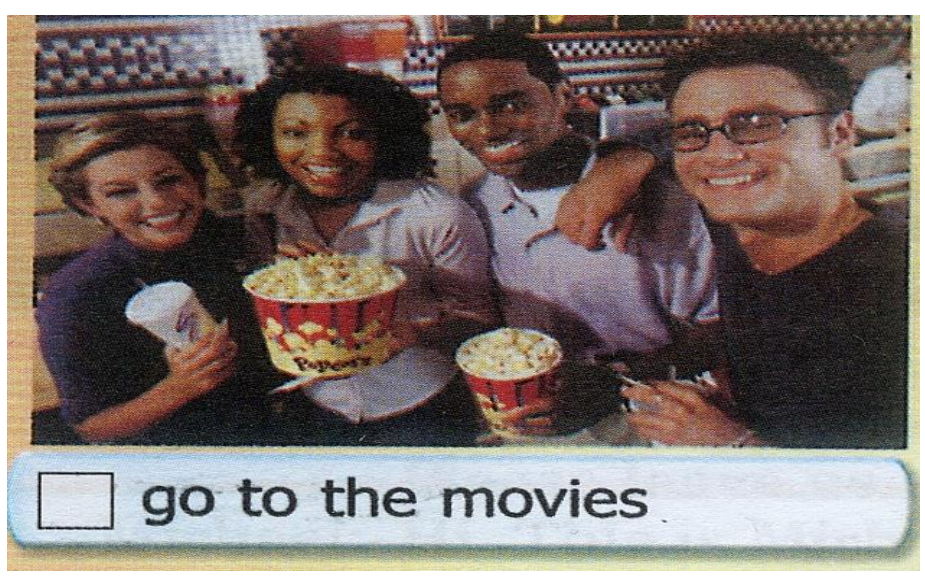

Figure 3: Interchange Intro Student's Book (Richards, 2005, p.

108).

As an example, a descriptive analysis of the most salient semiotic features of Figure 3 (i.e. symbolic process and information value) can reveal the above-mentioned pattern. The way the participants are holding the tubs of popcorn and the drinks in their hands cannot be interpreted as actions, but rather as gestures used to draw the viewer's attention to what they have in their hands. On the other hand, the way the tubs of popcorn and the drinks are placed in the foreground makes them look out of place. The tubs of popcorn and the drinks are, therefore, the symbolic attributes of a symbolic attributive process in which the human participants are the carriers. All the participants are, thus, represented as consumers. However, the drink in the hand of the white man is made less salient as it is covered under his hand while the tub of popcorn in the hand of the black woman is made maximally salient and eye-catching not only because of its size but also because of its sharp color. Therefore, as far as the symbolic process in this image is concerned, the black woman is portrayed as the most consumerist participant while the white man is represented as the least consumerist one. 
20 Gender Representation in Interchange series: A Social Semiotics...

An analysis of information value in the same figure shows that the female participants as consumers are placed on the left side as given. The female participants are shown as though they are already known as consumers. The male participants, on the other hand, occupy the right side of the image as new, the part of information with which the viewer is not familiar yet. This may be ideological because unlike women as consumers, men as consumers are placed in the part of the information which is strange, 'at issue' and 'contestable' (Kress \& van Leeuwen, 2006, p. 181).Therefore, the trait of consumerist is more attributed to women in that they occupy the left side as given in both pictures.

\section{Men's cooking, as compared to women's cooking, is not represented as something acceptable (Figure 4).}

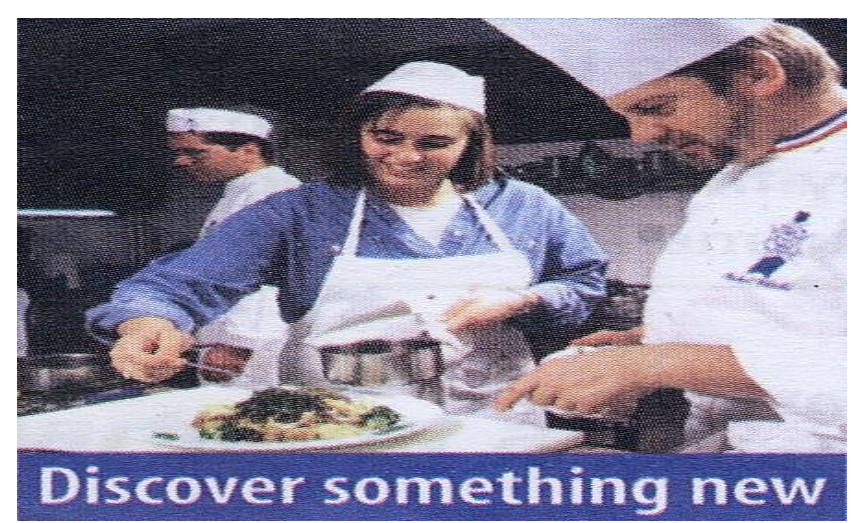

Figure 4: Interchange Student's Book 2 (Richards, 2005, p.

$30)$.

As is shown in Figure 4, the frontal plane of the woman in this figure is parallel to the frontal plane of the viewer. She is, thus, depicted as someone who belongs to the viewer's world or someone with whom the viewer is involved. The male participants, however, are shown from an oblique angle. They are, thus, represented as others, as detached from the viewer. They are, 
in fact, portrayed as not belonging to the viewer's world. This photo may mirror the ideology that woman as cooks is a normal fact in the society while men as cooks is not an agreed-upon fact.

\section{The kind of relationship between men is shown different from that between men and women andwomen's facial expression is realized in a way that it reveals more admiration for men than men's (Figure 5).}

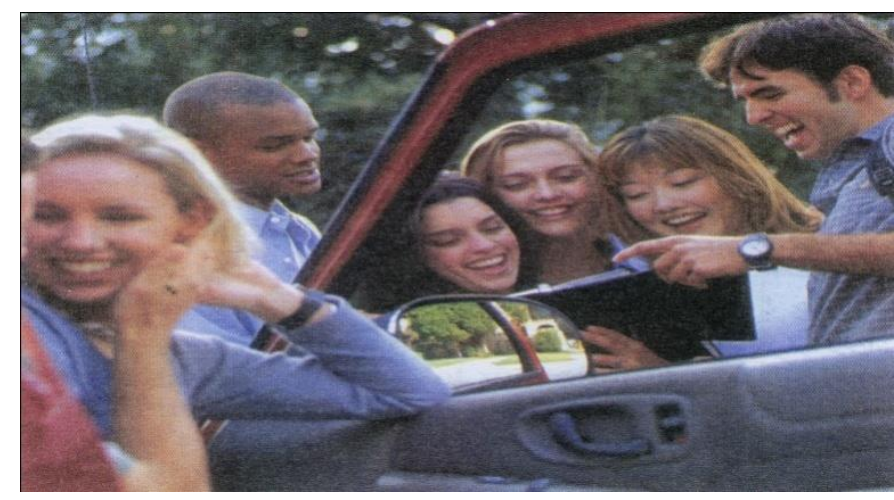

Figure 5: Interchange Student's Book 3 (Richards, 2005, p.

73).

As is seen in Figure 5, the three women placed between the two men are arranged in a symmetrical fashion because their size, their distance from each other and their orientation towards the vertical/horizontal axes are similar. Therefore, they are depicted as equal to and subordinates of a classificational process in which the superordinate is female friends. The structure of this classificational process is a covert taxonomy because the superordinate is not explicitly mentioned or written on the image, but rather it can be inferred from the symmetrical composition of the participants. The two men are also placed in a symmetrical composition with respect to each other: their size and distance from female participants are almost equal and their orientation towards the vertical/horizontal axes is symmetrical. Thus, 
22 Gender Representation in Interchange series: A Social Semiotics...

they can be regarded as the subordinates of another covert taxonomy in which male friends is the superordinate. Accordingly, it can be inferred from this image that the kind of friendship between the women is different from that between the two men, on the one hand, and, on the other hand, the kind of friendship the white man has with his male black friend differs from that he has with his female friends.

Besides, such a distinction is intensified by framing. That is, the vertical edge of the car door forms a frameline which draws a line in the picture and divides it into two sections. The white man and the three women are in this way separated from the black man. Thus, the black man and the four participants on the right are represented as disconnected units of information. The connectedness between the three women and the white man is not only achieved by their being placed within the same section, but also by the vector formed by the man's hand which leads the eye from the most salient participant (the man) to the women.

In the same photograph, the eyelines of the three women and the black man form vectors directed at the driver's license (as is mentioned in the relevant exercise and sentence, i.e. 'After you get your driver's license, you find out that your friends want rides') which is in the hand of the white man; therefore, the participants from whom the eyelines emanate are the reactors of a reactional process in which the driver's license is the phenomenon. The facial expression of the reactors is another factor involved in this reactional process: the three women are smiling broadly while the black man is smiling slightly. As the reactor's smiling while gazing shows approval of the phenomenon (Kress \& van Leeuwen, 2006), these women are depicted with greater approving and admiring look on their faces for the man's driver's license than the black man. As Kress and van Leeuwen (2006) mention, such a facial expression represents the women's reaction of admiration and approval to the man's action. This reflects one of Goffman's (1979) Gender Advertisement categories, i.e. Function Ranking according to which women are depicted in inferior occupational roles to men in advertisement. 


\section{Taking part in a sit-in and possessing a driver's license are represented as symbols of masculinity (figures 5 and 6 ).}

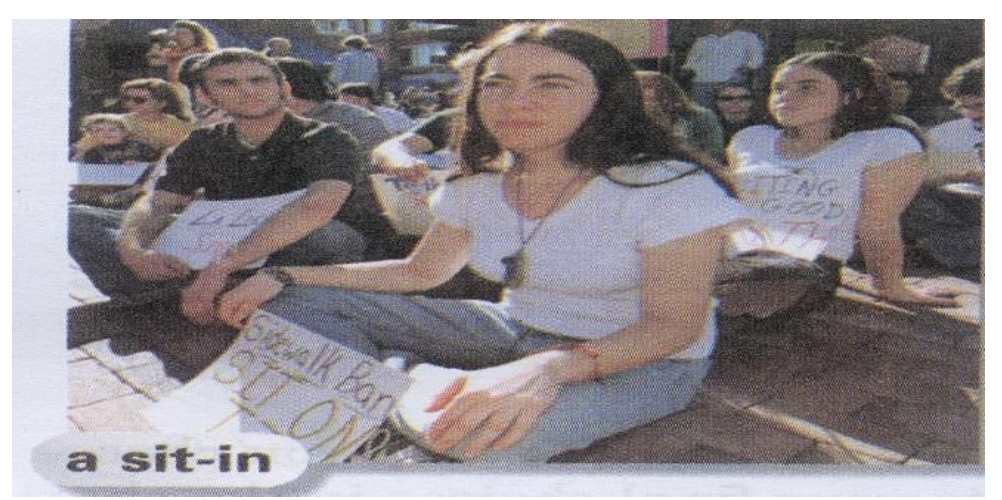

Figure 6: Interchange student's book 3 (Richards, 2005, p.

$$
\text { Interchange 7). }
$$

As can be seen, in Figure 6, the three prominent participants (the two women and the man who are shown in a sit-in, according to the caption) are arranged in a symmetrical position: their orientation towards the vertical/horizontal axes and their distance from each other are almost similar. Therefore, all the three participants are subordinates of a classificational process in which protesters is the superordinate which can be inferred by the viewer with respect to the caption. This shows that the three conspicuous represented participants, regardless of their gender, are portrayed as part of a united group.

Nevertheless, in front of all the three participants in the same photograph, there are pieces of paper on which slogans are written. The man seems to be involved in a symbolic process because his arm forms a vector aimed at the paper. This vector cannot be interpreted as an action, but only as touching the paper. The paper is, thus, the symbolic attribute of a symbolic process in 
24 Gender Representation in Interchange series: A Social Semiotics...

which the man is the carrier. As such, as far as the symbolic process is concerned, taking part in a sit-in is shown as a symbol of masculinity.That is, although all the three participants are represented as members of a united group, staging a sit-in is a male preserve. This idea may be intensified by the fact that compared to the women, the man is placed more to the left side of the photograph so that he is shown as the known information with which the viewer is already familiar.

On the other hand, the gaze of the two women in the same photograph is not directed at the viewer's eyes; they are depicted as objects of the look and are not inviting the viewer to identify with them. The male participant, however, is looking in the direction of the camera; he is, therefore, the subject of the look and is inviting the viewer to enter a relationship with him. As such, this image is an offer image with respect to the female participants and a demand image with respect to the male participant. Therefore, unlike the women, the man as a protester is inviting the viewers to identify with him, which contributes even more to focusing attention on the male participant.

Similarly, in Figure 5, a symbolic representation depicts an ideological depiction. In fact, vectors formed by the hands of two participants (one of the women and the white man) are aimed at the driver's license. These vectors cannot be interpreted as an action but as a gesture drawing the viewer's attention to the driver's license. Therefore, this visual structure is a symbolic process in which the driver's license is the symbolic attribute whose carrier is the white man because the vector made by his hand aimed at the symbolic attribute is more visible and salient than the hand of the woman which can barely be seen by the viewer. The driver's license, thus, can be interpreted as a symbol of power attributed to the man. 


\section{Women are depicted as belonging to home (Figure 7).}

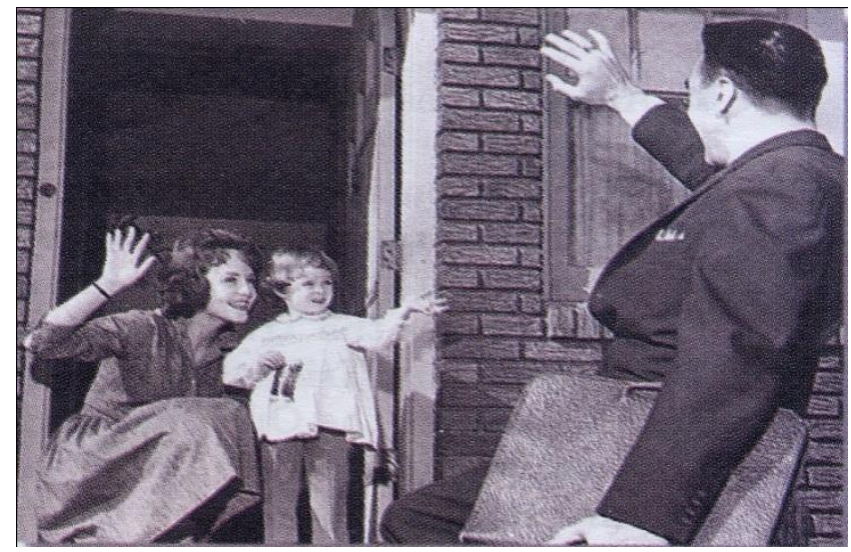

Figure 7: Interchange Student's Book 2 (Richards, 2005, p.

14).

The two female participants in Figure 7 are, on the one hand, separated from the man by the framelines formed by the right edge of the door and, on the other hand, they are represented as belonging to the context of home because they are positioned within the frame formed by the edges of the door and also the dark shade behind them. In fact, the edges of the door and the dark part within the frame of the door divide the picture into two parts: home and outside. The man is depicted as belonging to outside (activities) while the females are shown as belonging to home; these representations also seem to be stereotypical. 
26 Gender Representation in Interchange series: A Social Semiotics...

\section{Shyness (while laughing) is attributed to women (Figure 8).}

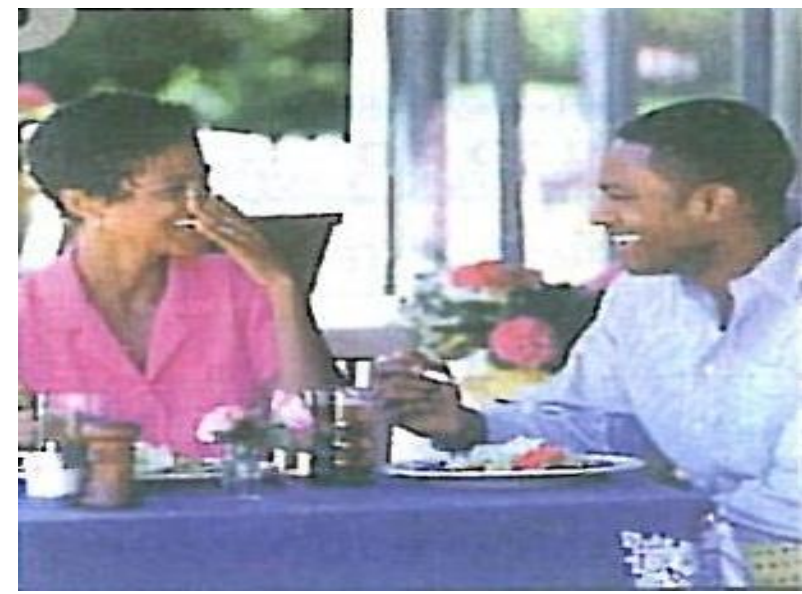

Figure 8: Interchange Intro Student's Book (Richards, 2005,

$$
\text { p. 73). }
$$

The woman in Figure 8 is pictured hiding her laughter behind her hand; her hand makes a vector which cannot be interpreted as an action. Therefore, she is the carrier of a symbolic process in which her hand is the symbolic attribute. This may be inferred as shyness, an attribute which is generally said to characterize females. This is in line with Goffman's (1979) category of Licensed Withdrawal, according to which women are photographed while using gestures (such as hiding behind their hands) which show their fear, shyness and submission to others. Besides, this symbolic process is placed on the left side which represents the information known by the viewer. 


\section{Following customs is more attributed to women (Figure 9).}

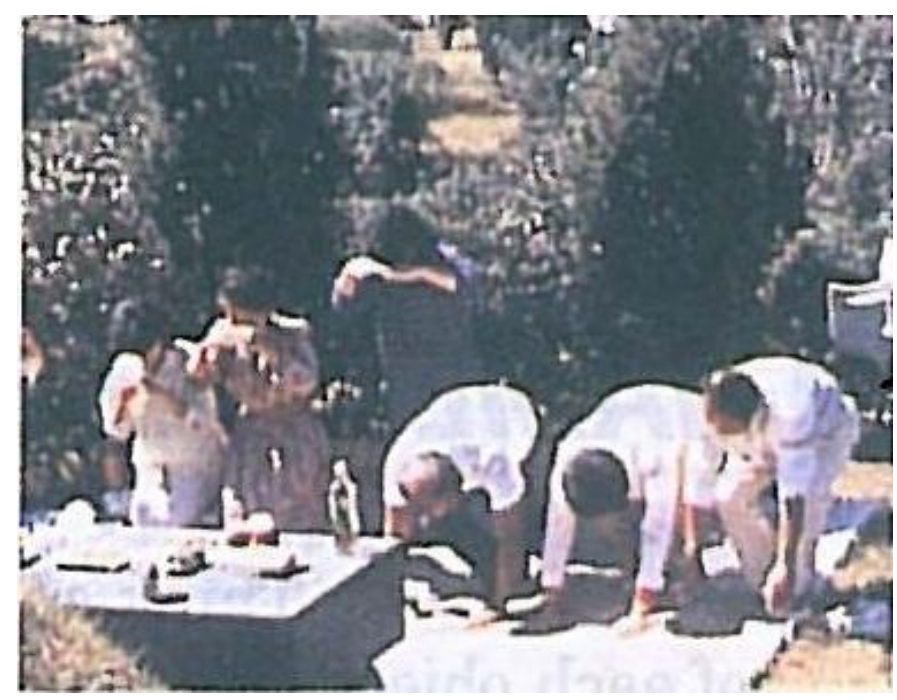

Figure 9: Interchange Student's Book 2 (Richards, 2005, p.

$55)$.

Figure 9 shows three men and three women while doing a part of a Korean custom. The represented participants of this photograph are depicted in active roles since all of them are shown in narrative representations involved in non-transactional action processes. Non-transactional action includes only actors and does not have any goal for which the action may be done. In fact, non-transactional action functions like sentences with intransitive verbs. A sentence with the continuous tense, e.g. 'They are praying before the graves of their ancestors', would be an appropriate equivalent of this representation if one wishes to translate it into the verbal mode. However, in this active representation, the three women are disconnected from the male participants by framing. In this photograph, framing is achieved by the discontinuity of the white color of men's clothes, the framelines formed by the white cloth spread on the ground and the 
28 Gender Representation in Interchange series: A Social Semiotics...

framlines formed by the grave in front of the women. Besides, the women are on the left: this may reflect the ideology that following customs is more attributed to women.

12. While in some pictures, men are disconnected from women through framing (figures 2, 5, 6, 7, 8, 9 and 13), in some others, men and women are connected together by color continuity or vectors (figures 1, 2, 4, 6, 12, 14).

In Figure 8, for example, the edge of the window forms a frameline dividing the picture into two parts which disconnects the man from the woman implying that they belong to distinct worlds. Similarly, the frameline formed by the right edge of the door in Figure 7and those formed by the white cloth spread on the ground and the grave in Figure 9 disconnect the male participant(s) from the female participants. Color continuity also functions as a kind of framing. For example, in Figure 6, the concept of connectedness between the two female participants is conveyed by continuity of the color of their t-shirts. However, the male participant is disconnected from the female participants by discontinuity of color (the female participants are wearing white t-shirts but the male participant is wearing a dark one). The two women are, therefore, shown as belonging to the same world and disconnected from the man's world. Such representations mirror the negative ideology which highlights male-female distinction.

On the other hand, in some other pictures, men and women are connected by color continuity suggesting that they do belong to the same world which can be interpreted as a positive ideology. In Figure 6, for example, connectedness of the three represented participants is realized by the continuity of the white color of their clothes. Although, the woman's dress is blue, the white color of her apron connects her with the male participants whose clothes are white. Therefore, the woman and the men are represented as a single unit of information and as joined together. Here, the positive ideology blurs the boundaries between the two genders. 


\section{Discussion and conclusion}

Findings of this study revealed some stereotypical representations in the photographs of the sample. The two goals of this study echoed in the two research questions stated above were, in the first place, to explore how men and women are represented in the photographs of the Interchange (Third Edition) series (Richards, 2005) based on Kress and van Leeuwen's (2006) social semiotics and, in the second place, to find out to what extent there is any gender bias in the photographs of the series based on the framework employed in the study.

With regard to the first goal, analysis of the sample photographs revealed various portrayals of men and women some of which reflected positive ideologies depicting both genders equally while some others reflected stereotypes. For instance, according to the results, men and women are connected together in some photographs of the series implying that they belong to the same world while disconnected in some others which may be indicative of the stereotypical distinction between men and women. The former reflects a positive ideology, whereas the latter a negative one. It was also found that although women were observed in (narrative) depictions in jobs which indicate stereotypes of women, men's active appearance in such jobs understated these stereotypes mirroring a shift toward a more positive ideology. This result contradicts the findings of some previous studies on ELT textbooks which revealed that contrary to women's appearance in stereotypical jobs and activities, men were found in a wide range of jobs (e.g., Amini \& Birjandi, 2012; Hartman and Judd, 1978; Jannati, 2015; Lee and Collins, 2008; Mineshima, 2008; Mukundan \& Nimehchisalem, 2008; Otlowski, 2003). This finding is also in sharp contrast with that of PintoCoelho and Mota-Ribeiro's (2009) results which indicated that unlike men, women were only conceptually represented in the visual mode.

The analysis also indicated some other negative ideologies in which women are underrepresented. One source of such negative ideologies is the stereotypical representation in which contrary to men as fathers who are mostly depicted in static, conceptual processes, women as mothers are shown in active, narrative representations. In fact, conceptual 
30 Gender Representation in Interchange series: A Social Semiotics...

representations serve to understate appearance in a particular role while narrative representations emphasize it. Besides, women depicted while cooking, following customs, taking care of their children in the role of mothers, and belonging to home are represented as a usual fact and part of the culture. By contrast, men's cooking is not represented as something acceptable: men who cook do not belong to the viewer's world. These depictions reflect a negative ideology: women's portrayals in trivial activities and domestic roles. These findings are in line with the results of some of the previous studies (e.g., Amini \& Birjandi, 2012; Ansari \& Babaii, 2003; Farooq, 1999; Hartman \& Judd, 1978; Jannati, 2015; Lee \& Collins, 2008; Mineshima, 2008; Mukundan \& Nimehchisalem, 2008; Otlowski, 2003; Porreca, 1984; Stockdale, 2006) in which, unlike men, women appeared in domestic roles and activities.

Further sources of male-biased ideologies are symbolic processes in which taking part in a sit-in and possessing a driver's license are attributed to men and consumerism and shyness (while laughing) to women. Thus, men are shown in significant and important activities while women are portrayed to be consumers and shy. It is worth mentioning that shyness while laughing may reflect low self-confidence. This finding is partly similar to Jannati's (2015) findings regarding the visual representation of men and women according to which being careless drivers was associated with women while tasks which need confidence were associated with men. Another male-biased ideology was revealed in women's facial expression suggesting more admiration for men. These findings are in accordance with two of the categories of Goffman's (1979) study, i.e. Licensed Withdrawal and Function Ranking and are, therefore, partially in line with some other studies which showed that Goffman's (1979) Gender Advertisement categories are still present in the visuals of advertisements (e.g., Bell \& Milic, 2002; Döring \& Pöschl, 2006; Kang, 1997; Linder, 2004). Moreover, these results lend support to the findings reported by Kordjazi (2012) according to which language learning materials may also include Goffman's (1979) Gender Advertisement categories.

With regard to the second objective of the study, taking the results 
of the present study into consideration, we may come up with the conclusion that as far as the sample is concerned, the Interchange (Third Edition) series (Richards, 2005) do include gender bias in favor of men. As the results of the study exhibited, despite the few equal portrayals of both genders, still, gender stereotypical depictions are observed which may be interpreted as gender bias in favor of men.This finding is, therefore, partially similar to the findings of some other studies on ELT textbooks which found malebiased depictions in ELT textbooks (e.g., Amini \& Birjandi, 2012; Ansari \& Babaii, 2003; Bahman \& Rahimi, 2010; Farooq, 1999; Hartman \& Judd, 1978; Kobia, 2009; Lee \& Collins, 2008; Mineshima, 2008; Mukundan \& Nimehchisalem, 2008; Otlowski, 2003; Porreca, 1984; Stockdale, 2006). However, this is inconsistent with the findings of some other studies which found that negative traits are attributed to men (e.g. Kobia, 2009; Mukundan \& Nimehchisalem, 2008). Furthermore, this finding contradicts the findings of Davatgarzadeh's (2007) study on the verbal mode of the same textbook series. Quite contrary to her findings which showed female-biased representations, results of the present study pointed to male-biased portrayals in the same textbooks. Therefore, it could be concluded that despite the fact that the linguistic mode of the series portrays women as more prominent, successful, powerful and intellectual (Davatgarzadeh, 2007), the visual mode still includes stereotypes and bias in favor of men.

Findings of this study may offer implications for material developers who design multimodal texts incorporating visual mode of communication because they may, wittingly or unwittingly, develop instructional materials which impose negative ideologies on learners. This study disclosed some of these hidden impositions; thus, the findings may be used as hints helping material developers avoid such drawbacks so that they can hopefully develop instructional materials which deliver knowledge in a neutral way.

Nevertheless, this study suffered from some limitations that should be taken into consideration particularly when results are interpreted. The most important limitation concerns the issue of 'intentionality' which is claimed to be one of the problems of ideological discourse analysis (Van Dijk, 2006, 
32 Gender Representation in Interchange series: A Social Semiotics...

p. 127). Van Dijk rightly comments that participants and analysts may ask themselves whether ideological features used in discourse are 'automatized' and, thus, not deliberately controlled or they are used intentionally. Then, he goes on to say that, participants are usually aware of the issue and when they are criticized for using ideological features, they take recourse to it as a justification for claiming that they did not intend it. It seems to be true in social semiotics analysis as well: textbook writers may (un)intentionally make use of photographs which show one gender in stereotypical portrayals. Nonetheless, since writers' intentions are not observable, as van Dijk (2006) remarks, the present researchers as well as other researchers may have to exclude writers' intentions from the variables incorporated in their research unless they can employ some means to reveal their intentions or lack thereof. However, van Dijk asserts that one has to consider both intentions (on the part of the sender of the message) and interpretations (on the part of the audience) to thoroughly analyze a text in terms of ideology.

Another limitation of the study is exclusion of photographs including either gender in isolation which was intentionally done to make the sample homogeneous. Indeed, the decision initially made led to the elimination of such semiotic categories as vertical angle, perspective and modality which could not be subject to comparison in the same photograph because both genders are exposed to the same vertical angle, perspective, and modality. Furthermore, to obtain more reliable results, 'one needs to look at the multimodal design of textbooks rather than at image or any other mode in isolation' (Bezemer \& Kress, 2009, p. 250). However, examination of all modes of representation was not the focus of the present study because scrutinizing multitude of items incorporated in the social semiotics framework employed in this study demanded exercising much precision that might have, otherwise, been lost at the expense of widening the scope beyond the analysis of images.

Finally, further research is warranted in the following areas. Researchers may analyze the graphicallyproduced pictures of the ELT textbooks from the social semiotics perspective employed in the current study. Even photographs are not innocent representations of the reality, but rather they 
depict reality in a particular way (Rose, 2001). The way a photograph is taken, in effect, mirrors the photographer's attitude towards the world and still there are many other possible sights for a scene to be photographed (Berger, 1972). Considering the choice made between alternative ways for realizing the reality, one may realize that options available to the producer are even greater in graphically produced pictures of ELT textbooks. Moreover, the same study may be expanded by examining the same books analyzed in the present study or any other ELT textbook from a multimodal perspective in terms of both visual and linguistic texts using Kress and van Leeuwen's (2006) social semiotics and other frameworks in the area of discourse analysis such as van Leeuwen's (1996) framework of social representation of actors, respectively, to find out whether the two modes of representation are in line with or contradict each other in terms of ideologies.

\section{Notes on Contributors}

Somayeh Bakhtiri completed her M.A. in TEFL at Shiraz University. She received her B.A. in English Language Translation from Bu-Ali Sina University. She is currently a freelance instructor and teaches general and specialized English courses as well as ESP courses to students of accounting at Islamic Azad University and Payam-e Noor University. Semiotics, teacher education, and psycholinguistics are among her areas of interest.

Mahboobeh Saadat is an assistant professor of TEFL. She is teaching undergraduate and graduate courses in the Department of Foreign Languages and Linguistics at Shiraz University, Shiraz, Iran. She is interested in teaching and doing research in the realm of literacy and language skills, particularly L2 reading and writing. She has published some papers in this area in the national and international journals.

\section{References}

Abdollahzadeh, E., \& Baniasad, S. (2010). Ideologies in imported English textbooks: EFL learners and teachers' awareness and attitude. Journal of English Language Teaching and Learning, 53(217), 1-17. 
34 Gender Representation in Interchange series: A Social Semiotics...

Amalsaleh, E. (2004). The Representation of social actors in the TEFL textbooks in Iran (Unpublished $\mathrm{PhD}$ Dissertation), Shiraz: Shiraz University, Iran.

Amini, M., \& Birjandi, P. (2012). Gender bias in the Iranian high school EFL textbooks. English Language Teaching, 5(2), 134-147.

Ansari, H., \& Babaii, E. (2003). Subliminal sexism in current ESL/EFL textbooks. Asian-EFL Journal, 5(1). Retrieved from http://www.asian-efljournal.com/march03.sub1.htm

Bahman, M., \& Rahimi, A. (2010). Gender representation in EFL materials: An analysis of English textbooks of Iranian high schools. Procedia Social and Behavioral sciences, 9, 273-277.

Bell, P. (2001). Content analysis of visual images. In T. van Leeuwen, \& C. Jewitt (Eds.), Handbook of visual analysis (pp.10-34). London: Sage.

Bell, P., \& Milic, M. (2002). Goffman's Gender Advertisements revisited: Combining content analysis with semiotic analysis. Visual Communication, 1(2), 203-222.

Bem, S. L., \& Bem, D. L. (1973). Does sex-biased job advertising "Aid and Abet" sex discrimination? Journal of Applied Social Psychology, 3(1), 6-18.

Berger, J. (1972). Ways of seeing. London: Penguin Books.

Bezemer, J., \& Kress, G. (2008). Writing in multimodal texts: A social semiotic account of design for learning. Written Communication, 25(2), 166-195.

Bohlke, R. F. (2006). A multimodal analysis of gendered messages in a diet advertisement for women. Proceedings (33rd International Systemic Functional Congress). Retrieved from 
http://www.pucsp.br/isfc/proceedings/Artigos\%20pdf/37m bohlke 775 a791 .$p d f$

Borhart, J.R. (2003). A rhetorical analysis of images of female athletes on the covers of Sports Illustrated(Master's thesis) University of Kansas, US. Retrieved from http://www.oregonpdf.org/printscript.cfm?path=../pdfl\&src=PE4737Borhart(18-2).pdf

Canning-Wilson, C. (1999). Using pictures in EFL and ESL classroom. In: Current trends in English language testing conference, Abu Dhabi, United Arab Emirates, June 2010, retrieved from http://www.files.eric.ed.gov/fulltext/ED445526.pdf

Davatgarzade, G. (2007). The representation of social actors in Interchange third edition series: A critical discourse analysis with respect to the sociosemantic features (Unpublished master's thesis), Shiraz: Shiraz University, Iran.

Döring, N., \& Pöschl, S. (2006). Images of men and women in mobile phone advertisement: A content analysis of advertisements for mobile communication systems in selected popular magazines. Sex Roles, 55(3/4), 173-185.

Fairclough, N., \&Wodak, R. (1997). Critical discourse analysis. In T. A. Van Dijk (Eds.), Discourse Studies: A Multidisciplinary Introduction (pp. 258-284). London: Sage.

Farooq, M. U. (1999). Examining sexism in an EFL textbook. Retrieved fromhttp://www.birmingham.ac.uk/Documents/ college artslaw/cels/essays/sociolinguistics/farooq6.pdf

Godeo, E. G. (2009). British men's magazines' scent advertising and the multimodal discursive construction of masculinity: A preliminary study. EstudiosIngleses de la Universidad Complutense, 17, 9-36. 
36 Gender Representation in Interchange series: A Social Semiotics...

Goffman, E. (1979). Gender Advertisements. London: Macmillan.

Hartman, P. L., \& Judd, E. L. (1978). Sexism and TESOL materials. TESOL Quarterly, 12(4), 383-393.

Jannati, S. (2015). Gender representation in EFL textbooks: A case of ILI pre-intermediate series. Journal of Applied Linguistics and Language research. 2(3), 211-222.

Jewitt, C., \& Oyama, R. (2001). Visual meaning: A social semiotic approach. In T. Van Leeuwen, \& C. Jewitt (Eds.), Handbook of Visual Analysis (pp.134-156). London: Sage.

Kang, M. (1997). The portrayal of women's images in magazine advertisements: Goffman's gender analysis revisited. Sex Roles,37(11/12), 979-996.

Kobia, J. M. (2009). Femininity and masculinity in English primary school textbooks in Kenya. The International Journal of Language Society and Culture,28,57-71.

Kordjazi, Z. (2012). Images matter: A semiological content analysis of gender positioning in contemporary English-learning software applications. Novitas-Royal (Research on Youth and Language), 6(1), 59-80.

Kress, G., \& Bezemer, J. (2009). Knowledge, creativity and communication in education: multimodal design. In C. Jewitt (Eds.), Beyond Current Horizon (pp. 1-11). Futurelab.

Kress, G., \& van Leeuwen, T. (1996). Reading Images: The Grammar of Visual Design. New York: Routledge.

Kress, G., \& van Leeuwen, T. (2006). Reading Images: The Grammar of Visual Design ( $2^{\text {nd }}$ ed.). New York: Routledge. 
Lee, J. F. K., \& Collins, P. (2008). Gender voices in Hong Kong English textbooks: Some past and current practices. Sex Roles, 59, 127-137.

Lin, Y., \& Ihara, H. (2009). The visual design of science picture books. Proceedings of IASDR2009, CD-ROM, n.p., 2009.10. Retrieved fromhttp://www.hdl.handle.net/2324/20306] (accessed 10 July 2011).

Linder, K. (2004). Images of women in general interest fashion magazine advertisements from 1955 to 2002. Sex Roles, 51(7/8), 410-421.

Low, J., \& Sherrard, P. (1999). Portrayal of women in sexuality and marriage and family textbooks: A content analysis of photographs from the 1970s to the 1990s. Sex Roles, 40(3-4), 309-318.

MartínezLirola, M. (2009). Immigration news in the free press: Linguistic and visual characteristic. Brno Studies in English, 35(1), 63-76.

MartínezLirola, M. (2010). Positive aspect of women of different cultures: An analysis of two multimodal covers. The Poster, 1(1),77-93.

Manolache, M. (2010). A semiotic analysis of the gender equality paradigm. Case study: The gender pay gap campaign. Styles of Communication, 2,7588 .

Mineshima, M. (2008). Gender representation in an EFL textbook. Bulletin of Niigata Institute of Technology, 13, 121-140.

Mukundan, J., \& Nimechisalem, V. (2008). Gender representation in Malaysian secondary school English language textbooks. Indonesian Journal of English Language Teaching,4 (2), 155-173.

Otlowski, M. (2003). Ethnic diversity and gender bias in EFL textbooks. Asian EFL Journal, 5(2), 1-15. 
38 Gender Representation in Interchange series: A Social Semiotics...

Oyama, R. (2007). The representation of motherhood and maternity in Japan and the UK. Online Proceedings of the Annual Conference of the Poetics and Linguistics Association (PALA). Retrieved from http://www.pala.ac.uk/resources/proceedings/2007/oyama 2007.pdf

Pinto-Coelho, Z., \& Mota-Ribeiro, S. (2009). Contradictions in the (Still) gendered structure of Portuguese newspapers' production and discourse. International Journal of Iberian Studies, 22(2), 125-143.

Porreca, K. L. (1984). Sexisim in current ESL textbooks. TESOL Quarterly, 18 (4), 705-724.

Renekma, J. (2004). Introduction to Discourse Studies. Amsterdam/Philadelphia: John Benjamins.

Richards, J. C. (2005). Interchange Third Edition Intro Student's Book. Cambridge: Cambridge University Press.

Richards, J. C. (2005). Interchange Third Edition Student's Book 1. Cambridge: Cambridge University Press.

Richards, J. C. (2005). Interchange Third Edition Student's Book 2. Cambridge: Cambridge University Press.

Richards, J. C. (2005). Interchange Third Edition Student's Book 3. Cambridge: Cambridge University Press.

Rose, G. (2001). Visual Methodologies. London: Sage.

Sahragard, R., \& Davatgarzadeh, G. (2010). The representation of social actors in Interchange Third Edition Series: A critical discourse analysis. The Journal of Teaching Language Skills (JTLS),2(1), 67-89. 
Stockdale, D. A. (2006). Gender representation in an EFL textbook. Master's thesis, University of Birmingham, UK. Retrieved from http://www.cels.bham.ac.uk/resources lessays / DAStockdaleSociolinguistics.pdf

Sullivan, G. L., \& O'cannor, P. J. (1988). Women's role portrayals in magazine advertising: 1958-1983. Sex Roles, 18(3/4), 181-188.

Tahririan, M. H., \& Sadri, E. (2013). Analysis of images in Iranian high school EFL course books. Iranian Journal of Applied Linguistics (IJAL), 16(2), 137-160.

Van Dijk, T. A. (1995). Discourse analysis as ideology analysis. In C. Schaffner, \& A. Wenden (Eds.), Language and Peace (pp. 17-33). Aldershot: Dartmouth Publishin.

Van Dijk, T. A. (2006). Ideology and discourse. Journal of Political Ideologies, 11(2), 115-140.

Van Leeuwen, T. (2005). Introducing Social Semiotics. London: Routledge. 